\title{
Hepatocellular Carcinoma in Non-alcoholic Fatty Liver Disease: Epidemiology, Pathogenesis, and Prevention
}

\author{
György Baffy \\ VA Boston Healthcare System and Brigham and Women's Hospital, Harvard Medical School, Boston, Massachusetts, USA
}

\begin{abstract}
Hepatocellular cancer ( $\mathrm{HCC})$ is the fifth most prevalent cancer worldwide and the third leading cause of cancer-related deaths. Non-alcoholic fatty liver disease (NAFLD), a spectrum of hepatic disorders associated with obesity and the metabolic syndrome, is a recognized risk factor for HCC. NAFLD that is advanced to cirrhosis carries the highest risk for HCC, but there is increasing concern that NAFLD-associated HCC may also occur in non-cirrhotic liver. As NAFLD is rapidly becoming the most common liver condition, it has been implicated in the worrisome trend of rising $\mathrm{HCC}$ incidence in a number of countries, which may offset successful measures in reducing the effect of virus-related liver cancer. Independently or in synergy with cirrhosis, NAFLD may provide a special oncogenic microenvironment through its pathogenic association with chronic nutrient excess and adipose tissue remodeling, characterized by pro-inflammatory adipokine profiles, lipotoxicity, altered hepatocellular bioenergetics, and insulin resistance. Better understanding of this complex process, and development of reliable biomarkers for $\mathrm{HCC}$ will be critical for early recognition and risk prediction. Moreover, correcting deranged lipid metabolism and restoring insulin sensitivity by lifestyle measures and targeted pharmacotherapy holds major promise for effective prevention of NAFLD-associated HCC.

(c) 2013 The Second Affiliated Hospital of Chongqing Medical University. Published by XIA \& HE Publishing Ltd. All rights reserved.
\end{abstract}

\section{Introduction}

Non-alcoholic fatty liver disease (NAFLD) is defined by abnormal hepatic lipid deposition without a history of excessive alcohol consumption. ${ }^{1}$ NAFLD is associated with

Keywords: Lipotoxicity; Insulin resistance; Cirrhosis; Hepatocarcinogenesis; Chemoprevention.

Abbreviations: AMPK, 5'-adenosine monophosphate activated protein kinase; ERK, extracellular signal-regulated kinases; FXR, farnesoid $X$ receptor; HCC, hepatocellular carcinoma; HCV, hepatitis C virus; IFL, isolated fatty liver; IGF, insulin-like growth factor; IL, interleukin; LDL, low-density lipoprotein; MEK, mitogen-activated protein/extracellular signal-regulated kinase kinase; mTOR, mammalian target of rapamycin; NAFLD, non-alcoholic fatty liver disease; NASH, non-alcoholic steatohepatitis; NF- $\mathrm{kB}$, nuclear factor- $\mathrm{\kappa B}$; PI3K, phosphoinositide 3-kinase; PPAR, peroxisome proliferator active receptor; SREBP, steroid response element binding protein; STAT, signal transducer and activator of transcription (STAT); PTEN, phosphatase and tensin homolog; TNF, tumor necrosis factor. Received: 5 May 2013; Revised: 11 June 2013; Accepted: 11 June 2013 DOI of original article: 10.14218/JCTH.2013.00005.

Correspondence to: György Baffy, VA Boston Healthcare System, Section of Gastroenterology, 150 S. Huntington Ave., Room 6A-46, Boston, Massachusetts 02130, USA. Fax: +1-857-364-4179, E-mail: gbaffy@partners.org obesity, and has been regarded as the hepatic presentation of metabolic syndrome. ${ }^{2}$ NAFLD has become extremely common in developed societies, affecting between 20 and $34 \%$ of adults $^{3,4}$ and up to $13 \%$ of children, ${ }^{5}$ while also reaching high prevalence in other parts of the world. ${ }^{6,7}$

The term NAFLD refers to a spectrum of liver disorders, ranging from isolated fatty liver (IFL) to non-alcoholic steatohepatitis (NASH). ${ }^{1,8}$ IFL represents about $80 \%$ of all cases of NAFLD, and carries minimal risk for advanced liver disease, although NAFLD in general has been associated with an adverse cardiovascular risk profile..$^{9,10} \mathrm{NASH}$ of varying severity accounts for the remaining cases and displays complex pathology beyond steatosis including hepatocellular injury, inflammation, and fibrosis. ${ }^{1,8} \mathrm{NASH}$ progresses to cirrhosis in $10-20 \%$ of cases within 10 years and may lead to major complications such as portal hypertension, liver failure, and hepatocellular carcinoma (HCC). ${ }^{1,11}$

Based on long-term follow-up studies, HCC is a rare complication of NAFLD. ${ }^{12,13}$ However, $\mathrm{HCC}$ is becoming more common in the USA, with an age-adjusted incidence rising from 1.5 to 4.9 per 100,000 individuals over the past 30 years. ${ }^{14}$ This trend has been attributed to increased incidence of chronic hepatitis $\mathrm{C}$ virus (HCV) infection, although the cause of HCC remains unclear in $50 \%$ of cases, and NAFLD is increasingly implicated in the rising HCC prevalence. ${ }^{15-17}$ It is therefore critical to improve our understanding of the link between NAFLD and HCC.

\section{Epidemiology of HCC associated with NAFLD}

HCC emerging in NAFLD that has advanced to cirrhosis

Autopsy records and imaging data indicate that $70-80 \%$ of individuals with obesity have increased liver fat content, suggesting that every third person in the general adult population of the USA and other industrialized countries has some form of NAFLD. ${ }^{4,18}$ Recent reports indicate that NASH can be verified by histological evaluation in up to $47 \%$ of all NAFLD cases among obese individuals. ${ }^{19,20}$ Moreover, there are 26 million individuals with manifest diabetes in the USA, and the presence of biopsy-proven NAFLD among people with diabetes has been reported to reach up to $74 \%$, with evidence of NASH in every fourth case. ${ }^{21,22}$ The pool of individuals at risk of NAFLD advancing to NASH and cirrhosis is therefore a substantial one.

There is good evidence that HCC may complicate NAFLD cirrhosis in the absence of other risk factors. ${ }^{11,23}$ In a prospective study conducted over 10 years, HCC developed in 10 out of 149 patients with NAFLD cirrhosis in comparison with 25 out of 147 American patients with HCV cirrhosis. ${ }^{24}$ In 
another analysis from the USA, the yearly cumulative incidence of NAFLD cirrhosis was 2.6\%, whereas that of $\mathrm{HCV}$ cirrhosis was $4.0 \% .^{25}$ In a Japanese study, HCC developed in $11.3 \%$ of patients with NAFLD cirrhosis compared with $30.5 \%$ of patients with HCV cirrhosis over 5 years. ${ }^{26}$ The overall contribution of NAFLD to the burden of liver cancer appears therefore comparable with that of major established causes of HCC such as chronic hepatitis B virus, chronic HCV, and alcoholic liver disease (Fig. 1).

Based on the significant worldwide prevalence of obesity and diabetes, there is an increasing probability that NAFLD coexists with chronic liver disease of other etiologies, increasing the risk of HCC. A study in Taiwan found that body mass index $(B M I) \geqslant 30 \mathrm{~kg} / \mathrm{m}^{2}$ was independently associated with a four-fold increased risk of HCC among HCVseropositive subjects, while this risk was only two-fold higher among obese subjects who were HCV-seronegative. ${ }^{27}$ In a French study, the combined presence of increased BMI and clinically manifest diabetes predicted an adjusted hazard ratio of 6.0 for HCC among 431 patients with cirrhosis associated with HCV and alcohol.28

NAFLD is recognized as a major cause of cryptogenic cirrhosis, a condition in which histological features of IFL or $\mathrm{NASH}$ may have disappeared, and only thorough medical historytaking can verify this relationship. ${ }^{29,30}$ Cryptogenic cirrhosis in developed societies is linked to $30-40 \%$ of diagnosed HCC cases without other obvious risk factors. ${ }^{17}$ Cryptogenic cirrhosis may be the cause of HCC diagnosed at more advanced stages, as demonstrated in a single-center study in which HCC was primarily identified by clinical symptoms, rather than via surveillance of patients with cryptogenic cirrhosis. ${ }^{31}$

\section{HCC emerging in non-cirrhotic NAFLD}

An additional concern is that HCC may complicate NAFLD with minimal or no fibrosis. ${ }^{11,32}$ Analysis of a healthcare claims database accounting each year for 18 million American lives identified 4,406 cases of HCC between 2002 and 2008, with NAFLD being the most common underlying risk factor $(59 \%)$ followed by diabetes (36\%) and chronic HCV $(22 \%) .{ }^{33}$ Intriguingly, the majority of NAFLD-associated HCC cases
(54\%) had no International Classification of Diseases code for cirrhosis, in comparison with only $22 \%$ of HCV-associated HCC documented in the absence of cirrhosis. ${ }^{33}$ In a compilation of case reports and case series from various geographical areas, the degree of fibrosis was F2 or lower in $28 \%$ of cases with NAFLD-associated HCC. ${ }^{11}$ Finally, in a recent study of 17,895 patients with HCC identified from the SEER-Medicare database, non-cirrhotic NAFLD was the only etiology in 1,031 cases $(5.8 \%)$, of which 186 cases (approximately $1 \%$ of the total HCC cohort) developed in isolated fatty liver. ${ }^{34}$

HCC risk remains very low when the analysis includes patients with all stages of NAFLD, not just those with biopsyproven NASH. In a cohort study conducted on Japanese patients with echogram-based diagnosis of NAFLD, the annual incidence rate of $\mathrm{HCC}$ was $0.043 \%$, amounting to a cumulative rate of $0.51 \%$ after a period of 12 years. ${ }^{35} \mathrm{~A}$ systematic review found that NAFLD cohorts with few or no cases of cirrhosis had a cumulative HCC mortality of $0-3 \%$ for study periods of up to 20 years. ${ }^{36}$ Based on large-scale epidemiological and long-term follow-up studies, HCC affects no more than 1 out of 3,000-4,000 individuals who have NAFLD in the absence of other liver disease. ${ }^{12,13}$ With the growing prevalence of obesity and diabetes, however, these numbers may increase, and additional studies are warranted to predict and understand the societal impact of NAFLD on HCC.

\section{Pathogenesis of HCC associated with NAFLD}

\section{General considerations}

NAFLD has a complex pathogenesis, with cellular and molecular mechanisms providing multiple links to the development of liver cancer. ${ }^{37,38}$ Most cases of NAFLD-associated HCC occur in cirrhosis, which provides a unique and strong tumorigenic microenvironment. ${ }^{39}$ However, NAFLD usually develops in the context of obesity and diabetes, which are independently associated with increased risk for cancer in a variety of tissues, including the liver. ${ }^{40,41}$ Therefore, interaction of oncogenic pathways related to adipose tissue dysfunction and established cirrhosis may provide a particularly conducive setting for the emergence of HCC (Fig. 2).

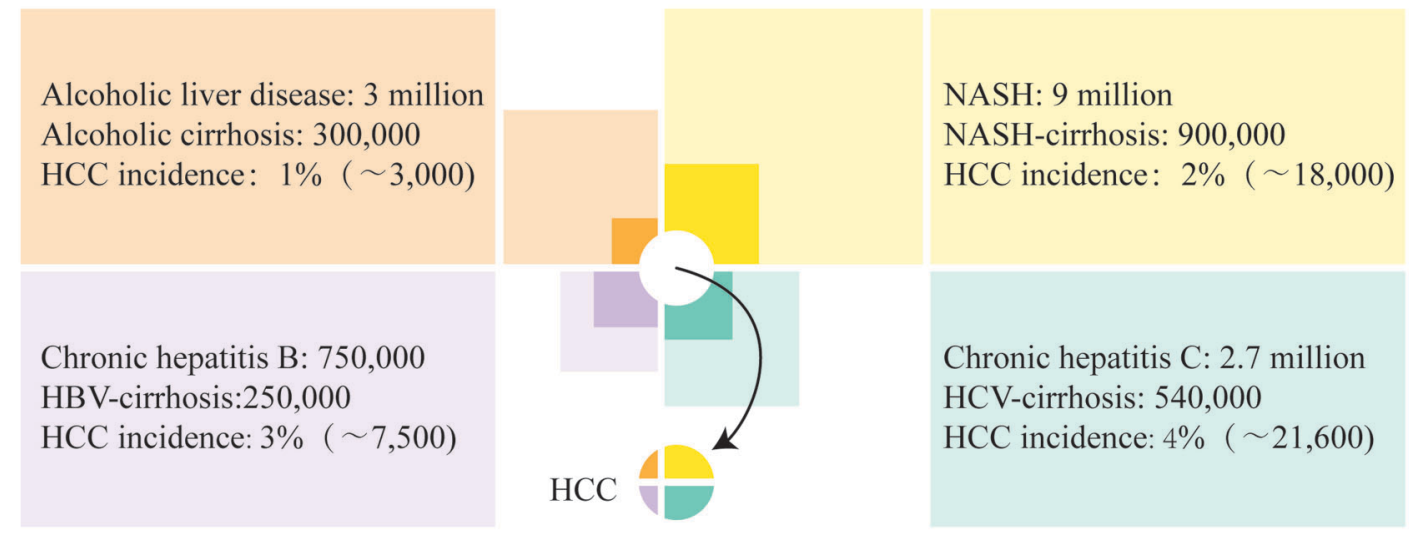

Fig. 1. Disease burden of HCC by major etiologies in the USA. The number of individuals with chronic liver disease (prevalence shown by light colored squares) including those with cirrhosis (prevalence shown by dark color squares) who develop HCC in any given year (incidence shown by small pie chart in the center) is illustrated by areas corresponding to low estimates from data published for alcoholic liver disease, ${ }^{111,112} \mathrm{NASH}_{,}^{4,24,25}$ chronic hepatitis B, ${ }^{113,114}$ and chronic $\mathrm{HCV}^{24,25,115,116}$ Accordingly, the highest number of cases of HCC are associated with chronic HCV, with the next highest number being associated with NAFLD. Note that the actual incidence of HCC is less than the sum of these estimates, indicating overlap between groups of individuals with chronic liver disease of various etiologies. 


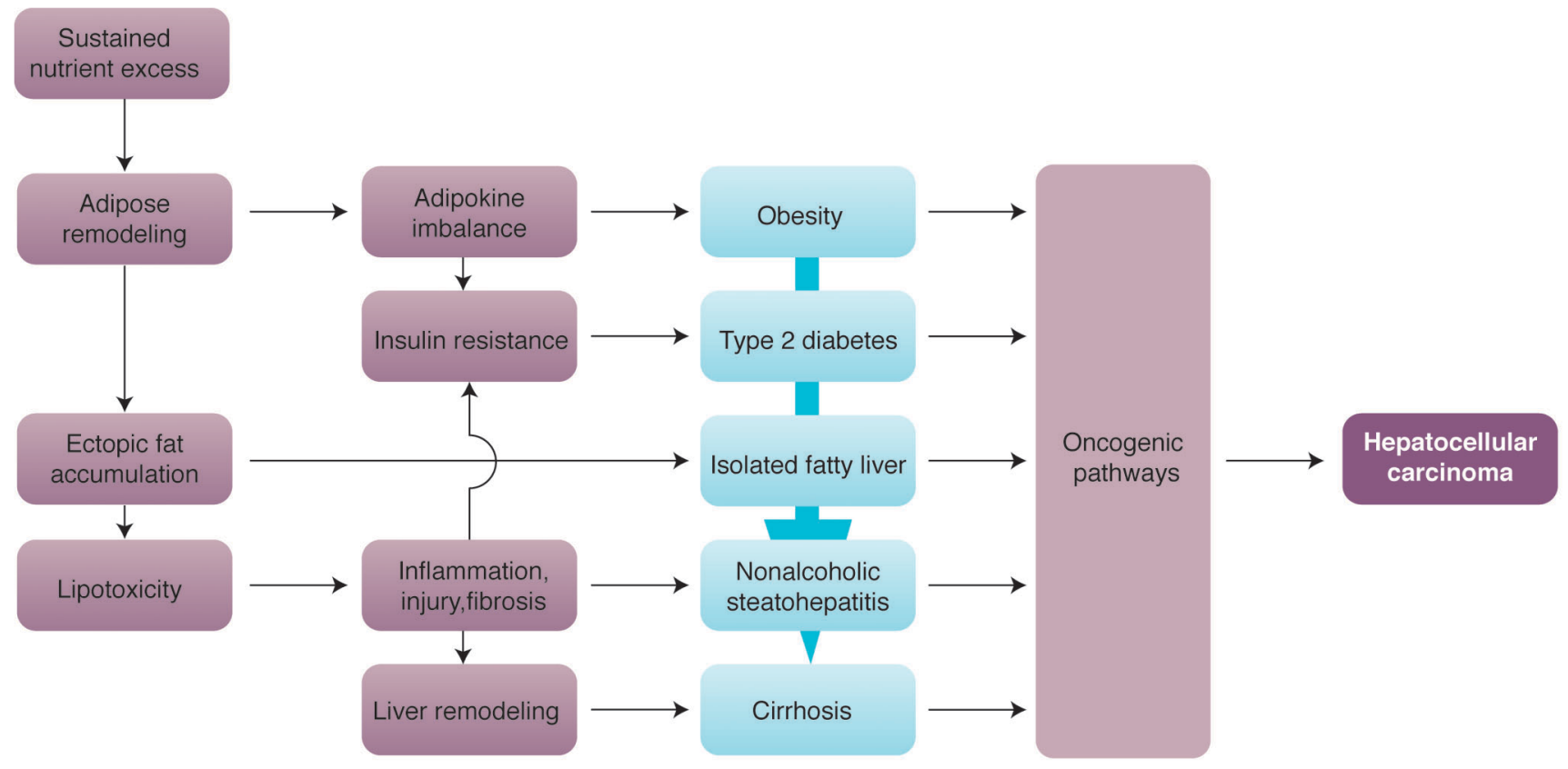

Fig. 2. Major mechanisms of hepatocarcinogenesis in NAFLD. Schematic illustration of metabolic derangements resulting from sustained nutrient excess, which involves remodeling of adipose tissue linked to the development and progression of NAFLD culminating in HCC. Key elements include a pro-inflammatory milieu promoted by adipokine imbalance and lipotoxicity caused by ectopic fat accumulation, both contributing to insulin resistance as a hallmark of pathogenesis. Various oncogenic pathways are activated at successive steps of progression, with interactions and cumulative effects accounting for the highest risk of HCC in cirrhosis, but allowing emergence of HCC at earlier disease stages.

\section{Molecular mechanisms of hepatocarcinogenesis in cirrhosis}

There is substantial evidence that cirrhosis is one of the most important risk factors of HCC. ${ }^{39,42}$ Erratic liver remodeling in cirrhosis creates a microenvironment with repeated cycles of hepatocellular destruction and compensatory regeneration to foster the development of HCC. ${ }^{43,44}$ This complex process involves many different cell types and oncogenic pathways. Triggered by chronic hepatocellular or cholangiocellular injury, resident liver macrophages (Kupffer cells), hepatic stellate cells, sinusoidal endothelial cells, and intrahepatic lymphocytes gradually change their phenotypes and acquire pro-oncogenic properties. Along with the recruitment of additional players, these cells produce a variety of cytokines, chemokines, growth factors, free radicals, and other bioactive substances that drive the initiation and progression of HCC. ${ }^{45}$ Through stepwise changes that may take many years, emergence of HCC follows a dysplasia-carcinoma sequence seen in other cancers. ${ }^{43,44}$ Accordingly, identification of molecular signatures that distinguish dysplastic nodules from early HCC in cirrhotic liver may allow enhanced surveillance, reliable prognostication, and timely intervention. ${ }^{46}$

Essentially, all major mechanisms of oncogenesis have been implicated in the development of HCC, including structural defects of the genome, epigenetic silencing or activation, and overly active or aberrant signal transduction cascades. 47,48 This extraordinary heterogeneity of HCC and the need to correlate molecular alterations with clinical characteristics have been the subject of several recent and excellent reviews. ${ }^{49,50}$ Initiation and progression of $\mathrm{HCC}$ involves numerous oncogenic pathways that may offer pharmacological targets for different subsets of patients. ${ }^{51,52}$
Thus, hepatocyte growth factor acting on c-met is critical for G1 to $\mathrm{S}$ transition in the cell cycle, making this receptor a candidate for targeted chemotherapy. ${ }^{53}$ Oncogenic signaling that depends on activation of Frizzled receptors by Wnt occurs through $\beta$-catenin, c-Jun $\mathrm{N}$-terminal kinases (JNKs), and protein kinase $\mathrm{C}^{54}$ Single nucleotide polymorphisms in the gene encoding epidermal growth factor, another major cell growth stimulator acting through cell surface receptors such as erbB1 and Her2/neu, have been linked to a variable risk of HCC. ${ }^{55}$ Recent research suggests that defects in the post-transcriptional regulation of gene expression via microRNA (miRNA) also contribute to development of HCC, and that different miRNA signatures may point to the underlying etiology. ${ }^{56,57}$

\section{Adipose tissue remodeling and molecular mechanisms of hepatocarcinogenesis}

So far, no structural or functional aberrations of liver cells have been specifically associated with the pathogenesis of HCC in NAFLD, although there are multiple candidates that may fulfill this role. Emergence of HCC in non-cirrhotic NAFLD suggests sufficient complexity to initiate hepatocarcinogenesis without the tumorigenic microenvironment of cirrhosis. Chronic nutrient excess results in expansion, redistribution, and remodeling of adipose tissue, which is associated with inflammation, lipotoxicity, and insulin resistance. ${ }^{58,59}$ These events are linked to numerous oncogenic pathways, and have a major role in the progression of NAFLD. Expansion of adipose tissue is characterized by disproportionate growth of visceral and deep subcutaneous fat depots, with an adverse adipokine secretory profile that includes higher levels of leptin and lower levels of adiponectin. ${ }^{60,61}$ Leptin 
has pro-inflammatory, pro-fibrogenic, and growth-promoting effects mediated by the Janus kinase/signal transducer and activator of transcription (JAK/STAT), phosphoinositide 3-kinase (PI3K)/Akt, and extracellular signal-regulated kinases (ERKs). ${ }^{62}$ By contrast, adiponectin, a potent activator of 5'-adenosine monophosphate activated protein kinase (AMPK), has anti-inflammatory, anti-angiogenic, and tumor growth-limiting properties by opposing the actions of leptin and suppressing signal transduction through Akt, STAT3, and mammalian target of rapamycin (mTOR). ${ }^{63}$ Thus, coinciding leptin surplus and adiponectin deficiency may activate numerous oncogenic pathways.

Adipose tissue remodeling also results in increased secretion of the pro-inflammatory cytokines interleukin-6 (IL-6) and tumor necrosis factor alpha (TNF- $\alpha$ ), which promote cell growth and inhibit apoptosis by targeting multiple signaling effectors such as ERKs, JNKs, nuclear factor- $\kappa B$ (NF- $\kappa B)$, signal transducer and activator of transcription 3 (STAT3), and mTOR. $^{37}$ The role of these cytokines in the development of HCC is supported by observations that obesity-associated promotion of malignant liver lesions in mice treated with diethylnitrosamine requires intact TNF and IL-6 signaling. ${ }^{64}$

\section{Oncogenic pathways associated with lipotoxicity}

When the capacity of expanding adipose tissue is exhausted, lipid molecules are stored in non-adipose tissues (e.g., liver, skeletal muscle, pancreas, and heart) and initiate lipotoxicity, defined as chronic cellular and tissue damage related to ectopic lipid accumulation. ${ }^{65-67}$ Liver lipotoxicity is advanced by de novo lipogenesis resulting from increased activation of steroid response element binding protein-1c (SREBP-1c) caused by elevated insulin levels. ${ }^{68,69}$ Removal of excess hepatic lipids in NAFLD may be hampered by insufficient mitochondrial $\beta$-oxidation (a common cause of microvesicular steatosis) and impaired export of very low-density lipoproteins. ${ }^{70,71}$ Moreover, lysosome-mediated degradation of lipid molecules in intracellular autophagosomes (lipophagy) is inhibited by excess fatty acids, representing a self-amplifying mechanism of lipotoxicity in hepatocytes. ${ }^{72}$

Experimental evidence indicates that lipotoxicity depends on the altered composition rather than the source or amount of ectopically deposited lipids. ${ }^{73}$ Thus, lipotoxicity has been attributed primarily to the harmful effect of free fatty acids and free cholesterol rather than triglycerides, which are considered relatively innocuous, and possibly actually protective. ${ }^{74,75}$ The panel of fatty acids implicated in lipotoxicity is broad, and tissue damage may depend on the length (short, medium, long, and very long), saturation (saturated, mono- and polyunsaturated), and isomerism (cis vs. trans) of acyl chains. ${ }^{76} \mathrm{~A}$ recent lipidomic analysis by thin-layer chromatography of liver tissue obtained from patients with NAFLD indicated that free cholesterol content and the ratio of $n-6$ to $n-3$ polyunsaturated fatty acids were significantly higher in NASH compared with IFL, and diminished levels of phosphatidylcholine and arachidonic acid allowed further distinction of NASH. ${ }^{73}$ Recent reports indicate that magnetic resonance-based methods may eventually provide similar qualitative information on hepatic lipid content, although this approach is still in the experimental phase. ${ }^{77,78}$ If fully developed, these non-invasive methods hold the promise of predicting disease severity in NAFLD.

Lipotoxicity results in various adverse conditions such as mitochondrial dysfunction, oxidative injury, endoplasmic reticulum stress, and insulin resistance. ${ }^{65,67}$ These mechanisms provide multiple links between lipotoxicity and hepatocarcinogenesis. For example, hepatocellular death induced by lipotoxicity (lipoapoptosis) correlates with the severity of NAFLD, and implicates the effects of liver macrophages activated by damaged and dying hepatocytes. ${ }^{79,80}$ Enhanced lipid peroxidation may activate macrophages by generating ligands (e.g., oxidized LDL) of scavenger receptors. ${ }^{81}$ Stimulation of the pivotal danger recognition receptor, toll-like receptor 4 , by saturated fatty acids is another mechanism of macrophage activation that may contribute to the liver inflammatory response. ${ }^{82}$ Importantly, macrophage-mediated stimulation of surviving hepatocytes via $\mathrm{NF}-\mathrm{\kappa B}$ and other cell-proliferation pathways is a major component of hepatocarcinogenesis, which has been established in various experimental models. ${ }^{83,84}$

As a fundamental consequence of obesity-associated adipokine imbalance, chronic inflammation, and lipotoxicity, insulin resistance results from multiple defects of the insulinmediated cellular signaling network, and leads to compensatory hyperinsulinemia. ${ }^{85,86}$ This process contains important self-amplification loops such as increased lipolysis from peripheral adipose depots due to uninhibited hormonesensitive lipase, and increased hepatic de novo lipogenesis due to retained insulin responsiveness of SREBP-1c. ${ }^{68}$ Elevated insulin levels stimulate the production of insulinlike growth factor (IGF)-binding protein and increase bioavailability of IGF1 and IGF2, further promoting oncogenic pathways such as PI3K/Akt, mitogen-activated protein kinase, and vascular endothelial growth factor. ${ }^{87}$

\section{Prevention of HCC associated with NAFLD}

\section{HCC reduction by weight management and physical exercise}

Measures aimed at preventing NAFLD progression may diminish the risk of HCC associated with this condition. Controlled caloric intake and regular exercise is the mainstay of therapy, although the extent to which these lifestyle changes may reduce the chance of developing HCC in NAFLD remains unclear. As recently reported, development of malignant liver lesions in hepatocyte-specific PTENdeficient mice fed for 32 weeks on a high-fat diet was significantly less in the group that had 60 minutes of exercise daily on a motorized treadmill compared with 'sedentary' controls ( $71 \%$ vs. $100 \%) .88$

The cancer-prevention effect of regular exercise is associated with physiological benefits, which include but are not limited to metabolic changes resulting from weight loss, such as decreased oxidative stress and improved adipokine balance. ${ }^{89}$ Although intentional weight loss in humans is difficult to achieve and keep, obesity can be reduced dramatically by bariatric surgery. Several large-scale studies indicate that cancer-prevention benefits can be expected from a weight loss of $10-30 \%$ sustained over 10 years. ${ }^{90,91}$ However, evidence for the effect of bariatric surgery on lowering the risk of HCC is limited. ${ }^{92}$

\section{HCC risk reduction by insulin-sensitizing agents}

Pharmacological therapy for the metabolic derangements associated with NAFLD such as insulin resistance and hyperlipidemia may provide additional opportunities to 
prevent hepatocarcinogenesis. There is evidence that insulinsensitizing agents reduce the risk of HCC in NAFLD associated with manifest diabetes. ${ }^{93-95}$ Most of these data relate to the effect of metformin, although thiazolidinediones may carry similar benefit. ${ }^{95,96}$ By contrast, use of insulin and sulfonylureas has been associated with increased risk of HCC. ${ }^{93,95}$ Metformin has been reported to have tumor inhibitory properties in a variety of cancers, and this effect was confirmed in a xenograft model of human hepatoma cells. ${ }^{97}$

The anti-proliferative action of metformin is linked to activation of AMPK, a master regulator of cellular energy metabolism, including inhibition of de novo lipogenesis, which has additional molecular targets such as the mTOR pathway and the retinoblastoma protein. ${ }^{98} \mathrm{~A}$ recent meta-analysis encompassing 105,495 patients with diabetes found that the risk of primary liver cancer was reduced by $62 \%$ (pooled odds ratio $0.38 ; 95 \%$ CI $0.24-0.59 ; p<0.001$ ) in those who were regularly taking metformin. ${ }^{99}$ It remains to be seen whether metformin has a similar chemopreventive effect on the risk of $\mathrm{HCC}$ in patients with NAFLD who have insulin resistance but no manifest diabetes.

The use of thiazolidinediones to improve insulin resistance has been associated with a reduction in risk for HCC of 44$70 \%$ in patients with diabetes. ${ }^{95,96}$ There are conflicting data on the molecular mechanisms by which these agents exert tumor prevention. Peroxisome proliferator active receptor $\gamma$ (PPAR $\gamma)$, a nuclear hormone receptor and the main target of thiazolidinediones, has been shown to inhibit tumor growth and metastasis formation in HCC, although some findings suggest that the effect of thiazolidinediones on HCC is PPAR $\gamma$ independent. ${ }^{100}$ Specific molecular mechanisms of tumor inhibition by thiazolidinediones include pro-apoptotic effects via activation of p53 and PTEN, as well as inhibition of $\mathrm{Bcl} 2$ and the ERK pathway. ${ }^{101}$ Because most members of this class of anti-diabetic drugs have been implicated in major adverse events, the role of thiazolidinediones in NAFLD management and HCC prevention remains controversial.

\section{Additional opportunities for chemoprevention of HCC in NAFLD}

Statins are inhibitors of endogenous cholesterol synthesis that work by targeting 3-hydroxy-3-methylglutaryl coenzyme-A (HMG-CoA) reductase, and are widely used for primary and secondary prevention of cardiovascular diseases. Statins have been reported to decrease the risk of a number of cancer types through anti-proliferative, proapoptotic, anti-angiogenic, and immunomodulatory mechanisms. ${ }^{102}$ Specific molecular targets of statins include $G$ proteins of the Ras/Rho superfamily, the RAF/MEK/ERK pathway, and the Myc oncoprotein. ${ }^{103,104}$ In a recent metaanalysis of 4,298 cases of HCC, statin users were less likely to develop HCC than non-users, with an adjusted odds ratio of $0.63\left(95 \%\right.$ CI, 0.52-0.76). ${ }^{102}$

Farnesoid $X$ receptor ( $F X R$ ) is a nuclear hormone receptor with high levels of expression in the liver, and has been implicated primarily in bile acid sensing. ${ }^{105}$ Similar to other nuclear hormone receptors, FXR regulates a large number of genes involved in lipid and glucose metabolism, liver regeneration, inflammation, and cancer. ${ }^{105-107}$ FXR-deficient mice display sustained activation of the $W n t / \beta$-catenin pathway, and reduced expression of the tumor suppressor $\mathrm{N}$-myc downstream-regulated gene 2 (NDRG2) with spontaneous development of HCC and other malignancies. ${ }^{108,109}$ FXR inhibits gankyrin, a proteasome factor that promotes degradation of multiple tumor suppressor proteins. ${ }^{110}$ Human studies indicate that FXR is downregulated in HCC, further supporting a protective role for FXR in tumor development. ${ }^{109}$ Overexpression of FXR in human hepatoma cells or stimulation by synthetic agonists such as GW4064 inhibited tumor growth in an orthotopic mouse xenograft model. ${ }^{108}$ These findings provide a basis for novel approaches in the prevention and treatment of HCC.

\section{Conclusions}

HCC is one of the most common malignancies in the world and has one of the worst survival rates of all the major cancers. HCC is among the few malignancies with an increasing incidence in the USA, a worrisome trend initially attributed to the aging population with chronic $\mathrm{HCV}$, but increasingly linked to the rapidly spreading epidemic of obesity, diabetes, and NAFLD. Although cirrhosis provides the most conducive microenvironment for hepatocarcinogenesis, NAFLD-associated HCC may emerge in its absence, fittingly described as "a wolf in sheep's clothing." Because NAFLD could be a game changer for liver cancer, it is imperative to develop reliable risk assessment and prevention tools, explore the pathogenesis in non-cirrhotic HCC, and identify new molecular targets for effective therapy.

\section{Conflict of interest}

None

\section{Author contributions}

Conceiving and writing review (GB).

\section{References}

[1] Angulo P. Nonalcoholic fatty liver disease. N Engl J Med 2002;346:1221-1231.

[2] Marchesini G, Brizi M, Morselli-Labate AM, Bianchi G, Bugianesi E, McCullough AJ, et al. Association of nonalcoholic fatty liver disease with insulin resistance. Am J Med 1999;107:450-455.

[3] Bellentani S, Saccoccio G, Masutti F, Croce LS, Brandi G, Sasso F, et al. Prevalence of and risk factors for hepatic steatosis in Northern Italy. Ann Intern Med 2000;132:112-117.

[4] Browning JD, Szczepaniak LS, Dobbins R, Nuremberg P, Horton JD, Cohen JC, et al. Prevalence of hepatic steatosis in an urban population in the United States: impact of ethnicity. Hepatology 2004;40:1387-1395.

[5] Schwimmer JB, Deutsch R, Kahen T, Lavine JE, Stanley C, Behling C. Prevalence of fatty liver in children and adolescents. Pediatrics 2006;118: 1388-1393.

[6] Chitturi S, Farrell GC, Hashimoto E, Saibara T, Lau GK, Sollano JD. Nonalcoholic fatty liver disease in the Asia-Pacific region: definitions and overview of proposed guidelines. J Gastroenterol Hepatol 2007;22:778-787.

[7] Liu CJ. Prevalence and risk factors for non-alcoholic fatty liver disease in Asian people who are not obese. J Gastroenterol Hepatol 2012;27:1555-1560.

[8] Torres DM, Williams CD, Harrison SA. Features, diagnosis, and treatment of nonalcoholic fatty liver disease. Clin Gastroenterol Hepatol 2012;10: 837-858.

[9] Yilmaz Y, Kurt R, Yonal O, Polat N, Celikel CA, Gurdal A, et al. Coronary flow reserve is impaired in patients with nonalcoholic fatty liver disease: association with liver fibrosis. Atherosclerosis 2010;211:182-186.

[10] Targher G, Marra F, Marchesini G. Increased risk of cardiovascular disease in non-alcoholic fatty liver disease: causal effect or epiphenomenon? Diabetologia 2008;51:1947-1953.

[11] Baffy G, Brunt EM, Caldwell SH. Hepatocellular carcinoma in nonalcoholic fatty liver disease: An emerging menace. J Hepatol 2012;56:1384-1391.

[12] Ekstedt M, Franzen LE, Mathiesen UL, Thorelius L, Holmqvist M, Bodemar G et al. Long-term follow-up of patients with NAFLD and elevated liver enzymes. Hepatology 2006;44:865-873. 
[13] Rafiq N, Bai C, Fang Y, Srishord M, McCullough A, Gramlich T, et al. Longterm follow-up of patients with nonalcoholic fatty liver. Clin Gastroenterol Hepatol 2009; 7:234-238.

[14] Altekruse SF, McGlynn KA, Reichman ME. Hepatocellular carcinoma incidence, mortality, and survival trends in the United States from 1975 to 2005. J Clin Oncol 2009;27:1485-1491.

[15] Bosch FX, Ribes J, Cleries R, Diaz M. Epidemiology of hepatocellular carcinoma. Clin Liver Dis 2005;9:191-211.

[16] Charlton M. Cirrhosis and liver failure in nonalcoholic fatty liver disease: Molehill or mountain? Hepatology 2008;47:1431-1433.

[17] El-Serag HB, Rudolph KL. Hepatocellular carcinoma: epidemiology and molecular carcinogenesis. Gastroenterology 2007;132:2557-2576.

[18] Bellentani S, Tiribelli C. The spectrum of liver disease in the general population: lesson from the Dionysos study. J Hepatol 2001;35:531-537.

[19] Gholam PM, Flancbaum L, Machan JT, Charney DA, Kotler DP. Nonalcoholic fatty liver disease in severely obese subjects. Am J Gastroenterol 2007; 102:399-408.

[20] Merriman RB, Ferrell LD, Patti MG, Weston SR, Pabst MS, Aouizerat BE, et al. Correlation of paired liver biopsies in morbidly obese patients with suspected nonalcoholic fatty liver disease. Hepatology 2006;44:874-880.

[21] Byrne CD, Olufadi R, Bruce KD, Cagampang FR, Ahmed MH. Metabolic disturbances in non-alcoholic fatty liver disease. Clin Sci (Lond) 2009;116: 539-564.

[22] Williams CD, Stengel J, Asike MI, Torres DM, Shaw J, Contreras M, et al. Prevalence of nonalcoholic fatty liver disease and nonalcoholic steatohepatitis among a largely middle-aged population utilizing ultrasound and liver biopsy: a prospective study. Gastroenterology 2011;140:124-131.

[23] Hashimoto E, Tokushige K. Hepatocellular carcinoma in non-alcoholic steatohepatitis: Growing evidence of an epidemic? Hepatol Res 2012;42: $1-14$.

[24] Sanyal A], Banas C, Sargeant C, Luketic VA, Sterling RK, Stravitz RT, et al. Similarities and differences in outcomes of cirrhosis due to nonalcoholic steatohepatitis and hepatitis C. Hepatology 2006;43:682-689.

[25] Ascha MS, Hanouneh IA, Lopez R, Tamimi TA, Feldstein AF, Zein NN. The incidence and risk factors of hepatocellular carcinoma in patients with nonalcoholic steatohepatitis. Hepatology 2010;51:1972-1978.

[26] Yatsuji S, Hashimoto E, Tobari M, Taniai M, Tokushige K, Shiratori K. Clinical features and outcomes of cirrhosis due to non-alcoholic steatohepatitis compared with cirrhosis caused by chronic hepatitis C. J Gastroenterol Hepatol 2009;24:248-254.

[27] Chen CL, Yang HI, Yang WS, Liu CJ, Chen PJ, You SL, et al. Metabolic factors and risk of hepatocellular carcinoma by chronic hepatitis B/C infection: a follow-up study in Taiwan. Gastroenterology 2008;135:111-121.

[28] N'Kontchou G, Paries J, Htar MT, Ganne-Carrie N, Costentin L, Grando-Lemaire $\mathrm{V}$, et al. Risk factors for hepatocellular carcinoma in patients with alcoholic or viral C cirrhosis. Clin Gastroenterol Hepatol 2006;4:1062-1068.

[29] Caldwell SH, Oelsner DH, Iezzoni JC, Hespenheide EE, Battle EH, Driscoll C]. Cryptogenic cirrhosis: clinical characterization and risk factors for underlying disease. Hepatology 1999;29:664-669.

[30] Poonawala A, Nair SP, Thuluvath PJ. Prevalence of obesity and diabetes in patients with cryptogenic cirrhosis: a case-control study. Hepatology 2000; 32:689-692.

[31] Marrero JA, Fontana RJ, Su GL, Conjeevaram HS, Emick DM, Lok AS. NAFLD may be a common underlying liver disease in patients with hepatocellular carcinoma in the United States. Hepatology 2002;36:1349-1354.

[32] Torres DM, Harrison SA. Nonalcoholic steatohepatitis and noncirrhotic hepatocellular carcinoma: fertile soil. Semin Liver Dis 2012;32:30-38.

[33] Sanyal A, Poklepovic A, Moyneur E, Barghout V. Population-based risk factors and resource utilization for HCC: US perspective. Curr Med Res Opin 2010;26:2183-2191.

[34] Rahman RN, Ibdah JA. Nonalcoholic fatty liver disease without cirrhosis is an emergent and independent risk factor of hepatocellular carcinoma: A population based study. Hepatology 2012;56:241A.

[35] Kawamura Y, Arase Y, Ikeda K, Seko Y, Imai N, Hosaka T, et al. Large-scale long-term follow-up study of Japanese patients with non-alcoholic fatty liver disease for the onset of hepatocellular carcinoma. Am J Gastroenterol 2012; 107:253-261.

[36] White DL, Kanwal F, El-Serag HB. Association between nonalcoholic fatty liver disease and risk for hepatocellular cancer, based on systematic review. Clin Gastroenterol Hepatol 2012;10:1342-1359.e2.

[37] Stickel F, Hellerbrand C. Non-alcoholic fatty liver disease as a risk factor for hepatocellular carcinoma: mechanisms and implications. Gut 2010;59: 1303-1307.

[38] Starley BQ, Calcagno CJ, Harrison SA. Nonalcoholic fatty liver disease and hepatocellular carcinoma: a weighty connection. Hepatology 2010;51: 1820-1832.

[39] Fattovich G, Stroffolini T, Zagni I, Donato F. Hepatocellular carcinoma in cirrhosis: incidence and risk factors. Gastroenterology 2004;127:S35-50.
[40] Calle EE, Rodriguez C, Walker-Thurmond K, Thun MJ. Overweight, obesity, and mortality from cancer in a prospectively studied cohort of U.S. adults. N Engl J Med 2003;348:1625-1638

[41] Renehan AG, Tyson M, Egger M, Heller RF, Zwahlen M. Body-mass index and incidence of cancer: a systematic review and meta-analysis of prospective observational studies. Lancet 2008;371:569-578.

[42] Severi T, van Malenstein H, Verslype C, van Pelt JF. Tumor initiation and progression in hepatocellular carcinoma: risk factors, classification, and therapeutic targets. Acta Pharmacol Sin 2010;31:1409-1420.

[43] Thorgeirsson SS, Grisham JW. Molecular pathogenesis of human hepatocellular carcinoma. Nat Genet 2002;31:339-346.

[44] Farazi PA, DePinho RA. Hepatocellular carcinoma pathogenesis: from genes to environment. Nat Rev Cancer 2006;6:674-687.

[45] Wu SD, Ma YS, Fang Y, Liu LL, Fu D, Shen XZ. Role of the microenvironment in hepatocellular carcinoma development and progression. Cancer Treat Rev 2012;38:218-225.

[46] Llovet JM, Chen Y, Wurmbach E, Roayaie S, Fiel MI, Schwartz M, et al. A molecular signature to discriminate dysplastic nodules from early hepatocellular carcinoma in HCV cirrhosis. Gastroenterology 2006;131: 1758-1767.

[47] Kondo Y, Kanai Y, Sakamoto M, Mizokami M, Ueda R, Hirohashi S. Genetic instability and aberrant DNA methylation in chronic hepatitis and cirrhosisA comprehensive study of loss of heterozygosity and microsatellite instability at 39 loci and DNA hypermethylation on $8 \mathrm{CpG}$ islands in microdissected specimens from patients with hepatocellular carcinoma. Hepatology 2000;32:970-979.

[48] Breuhahn K, Schirmacher P. Signaling networks in human hepatocarcinogenesis-novel aspects and therapeutic options. Prog Mol Biol Transl Sci 2010;97:251-277.

[49] Boyault S, Rickman DS, de Reynies A, Balabaud C, Rebouissou S, Jeannot E, et al. Transcriptome classification of HCC is related to gene alterations and to new therapeutic targets. Hepatology 2007;45:42-52.

[50] Hoshida Y, Toffanin S, Lachenmayer A, Villanueva A, Minguez B, Llovet JM. Molecular classification and novel targets in hepatocellular carcinoma: recent advancements. Semin Liver Dis 2010;30:35-51.

[51] Breuhahn K, Longerich T, Schirmacher P. Dysregulation of growth factor signaling in human hepatocellular carcinoma. Oncogene 2006;25 3787-3800.

[52] Zhu AX. Molecularly targeted therapy for advanced hepatocellular carcinoma in 2012: current status and future perspectives. Semin Oncol 2012; 39:493-502.

[53] Chen X, Ding G, Gao Q, Sun J, Zhang Q, Du L, et al. A human anti-c-Met Fab fragment conjugated with doxorubicin as targeted chemotherapy for hepatocellular carcinoma. PLoS One 2013;8:e63093.

[54] Bengochea A, de Souza MM, Lefrancois L, Le Roux E, Galy O, Chemin I, et al. Common dysregulation of Wnt/Frizzled receptor elements in human hepatocellular carcinoma. Br J Cancer 2008;99:143-150.

[55] Abu Dayyeh BK, Yang M, Fuchs BC, Karl DL, Yamada S, Sninsky J], et al. A functional polymorphism in the epidermal growth factor gene is associated with risk for hepatocellular carcinoma. Gastroenterology 2011 141:141-149.

[56] Jiang J, Gusev Y, Aderca I, Mettler TA, Nagorney DM, Brackett DJ, et al. Association of MicroRNA expression in hepatocellular carcinomas with hepatitis infection, cirrhosis, and patient survival. Clin Cancer Res 2008;14 419-427.

[57] Cheung O, Puri P, Eicken C, Contos MJ, Mirshahi F, Maher JW, et al Nonalcoholic steatohepatitis is associated with altered hepatic microRNA expression. Hepatology 2008;48:1810-1820.

[58] Shoelson SE, Herrero L, Naaz A. Obesity, inflammation, and insulin resistance. Gastroenterology 2007;132:2169-2180.

[59] Hotamisligil GS. Inflammation and metabolic disorders. Nature 2006;444 860-867.

[60] Van der Poorten D, Milner KL, Hui J, Hodge A, Trenell MI, Kench JG, et al. Visceral fat: a key mediator of steatohepatitis in metabolic liver disease. Hepatology 2008;48:449-457.

[61] Kelley DE, Thaete FL, Troost F, Huwe T, Goodpaster BH. Subdivisions of subcutaneous abdominal adipose tissue and insulin resistance. Am J Physiol Endocrinol Metab 2000;278:E941-E948.

[62] Saxena NK, Sharma D, Ding X, Lin S, Marra F, Merlin D, et al. Concomitant activation of the JAK/STAT, PI3K/AKT, and ERK signaling is involved in leptin-mediated promotion of invasion and migration of hepatocellular carcinoma cells. Cancer Res 2007;67:2497-2507.

[63] Dalamaga M, Diakopoulos KN, Mantzoros CS. The role of adiponectin in cancer: a review of current evidence. Endocr Rev 2012;33:547-594.

[64] Park EJ, Lee JH, Yu GY, He G, Ali SR, Holzer RG, et al. Dietary and genetic obesity promote liver inflammation and tumorigenesis by enhancing IL-6 and TNF expression. Cell 2010;140:197-208.

[65] Unger RH, Orci L. Lipotoxic diseases of nonadipose tissues in obesity. Int ] Obes Relat Metab Disord 2000;24 (Suppl):28-32. 
[66] Tan CY, Vidal-Puig A. Adipose tissue expandability: the metabolic problems of obesity may arise from the inability to become more obese. Biochem Soc Trans 2008;36:935-940.

[67] Browning JD, Horton JD. Molecular mediators of hepatic steatosis and liver injury. J Clin Invest 2004;114:147-152.

[68] Brown MS, Goldstein JL. Selective versus total insulin resistance: a pathogenic paradox. Cell Metab 2008;7:95-96.

[69] Postic C, Girard J. Contribution of de novo fatty acid synthesis to hepatic steatosis and insulin resistance: lessons from genetically engineered mice. J Clin Invest 2008;118:829-838.

[70] Pessayre D, Berson A, Fromenty B, Mansouri A. Mitochondria in steatohepatitis. Semin Liver Dis 2001;21:57-69.

[71] Fujita K, Nozaki Y, Wada K, Yoneda M, Fujimoto Y, Fujitake M, et al. Dysfunctional very-low-density lipoprotein synthesis and release is a key factor in nonalcoholic steatohepatitis pathogenesis. Hepatology 2009;50: 772-780.

[72] Singh R, Kaushik S, Wang Y, Xiang Y, Novak I, Komatsu M, et al. Autophagy regulates lipid metabolism. Nature 2009;458:1131-1135.

[73] Puri P, Baillie RA, Wiest MM, Mirshahi F, Choudhury J, Cheung O, et al. A lipidomic analysis of nonalcoholic fatty liver disease. Hepatology 2007;46: 1081-1090.

[74] Larter CZ, Chitturi S, Heydet D, Farrell GC. A fresh look at NASH pathogenesis. Part 1: The metabolic movers. J Gastroenterol Hepato 2010;25:672-690.

[75] Choi SS, Diehl AM. Hepatic triglyceride synthesis and nonalcoholic fatty liver disease. Curr Opin Lipidol 2008;19:295-300.

[76] Alkhouri N, Dixon LJ, Feldstein AE. Lipotoxicity in nonalcoholic fatty liver disease: not all lipids are created equal. Expert Rev Gastroenterol Hepato 2009;3:445-451.

[77] Johnson NA, Walton DW, Sachinwalla T, Thompson CH, Smith K, Ruell PA, et al. Noninvasive assessment of hepatic lipid composition: Advancing understanding and management of fatty liver disorders. Hepatology 2008; 47:1513-1523.

[78] Van Werven JR, Schreuder TC, Nederveen AJ, Lavini C, Jansen PL, Stoker J. Hepatic unsaturated fatty acids in patients with non-alcoholic fatty liver disease assessed by 3.0T MR spectroscopy. Eur J Radiol 2010;75:e102-e107.

[79] Malhi H, Bronk SF, Werneburg NW, Gores G]. Free fatty acids induce JNKdependent hepatocyte lipoapoptosis. J Biol Chem 2006;281:12093-12101.

[80] Cazanave SC, Gores G]. Mechanisms and clinical implications of hepatocyte lipoapoptosis. Clin Lipidol 2010;5:71-85.

[81] Terpstra V, van Amersfoort ES, van Velzen AG, Kuiper J, van Berkel TJ. Hepatic and extrahepatic scavenger receptors: function in relation to disease. Arterioscler Thromb Vasc Biol 2000;20:1860-1872.

[82] Shi H, Kokoeva MV, Inouye K, Tzameli I, Yin H, Flier JS. TLR4 links innate immunity and fatty acid-induced insulin resistance. J Clin Invest 2006;116: 3015-3025.

[83] Maeda S, Kamata H, Luo JL, Leffert H, Karin M. IKKbeta couples hepatocyte death to cytokine-driven compensatory proliferation that promotes chemical hepatocarcinogenesis. Cell 2005;121:977-990.

[84] Sun B, Karin M. Obesity, inflammation, and liver cancer. J Hepatol 2012;56: 704-713.

[85] Saltiel AR, Kahn CR. Insulin signalling and the regulation of glucose and lipid metabolism. Nature 2001;414:799-806.

[86] Calle EE, Kaaks R. Overweight, obesity and cancer: epidemiological evidence and proposed mechanisms. Nat Rev Cancer 2004;4:579-591.

[87] Khandekar M], Cohen P, Spiegelman BM. Molecular mechanisms of cancer development in obesity. Nat Rev Cancer 2011;11:886-895.

[88] Piguet AC. Effect of regular training on hepatocellular carcinoma development in hepatocyte-specific PTEN-deficient mice. International Liver Congress Amsterdam, 2013.

[89] Basen-Engquist K, Chang M. Obesity and cancer risk: recent review and evidence. Curr Oncol Rep 2011;13:71-76.

[90] Adams TD, Gress RE, Smith SC, Halverson RC, Simper SC, Rosamond WD, et al. Long-term mortality after gastric bypass surgery. N Engl J Med 2007; 357:753-761.

[91] Sjostrom L. Review of the key results from the Swedish Obese Subjects (SOS) trial: a prospective controlled intervention study of bariatric surgery. J Intern Med 2013;273:219-234.

[92] Burza MA. PNPLA3 I148M (rs738409) genetic variant is associated with hepatocellular carcinoma in obese individuals. Dig Liver Dis 2012;44: 1037-1041.
[93] Donadon V, Balbi M, Mas MD, Casarin P, Zanette G. Metformin and reduced risk of hepatocellular carcinoma in diabetic patients with chronic liver disease. Liver Int 2010;30:750-758.

[94] Nkontchou G, Cosson E, Aout M, Mahmoudi A, Bourcier V, Charif I, et al. Impact of metformin on the prognosis of cirrhosis induced by viral hepatitis $C$ in diabetic patients. J Clin Endocrinol Metab 2011;96:2601-2608.

[95] Hassan MM, Curley SA, Li D, Kaseb A, Davila M, Abdalla EK, et al. Association of diabetes duration and diabetes treatment with the risk of hepatocellular carcinoma. Cancer 2010;116:1938-1946.

[96] Lai S-W, Chen P-C, Liao K-F, Muo C-H, Lin C-C, Sung F-C. Risk of hepatocellular carcinoma in diabetic patients and risk reduction associated with anti-diabetic therapy: A population-based cohort study. Am J Gastroenterol 2011;107:46-52.

[97] Chen HP, Shieh JJ, Chang CC, Chen TT, Lin JT, Wu MS, et al. Metformin decreases hepatocellular carcinoma risk in a dose-dependent manner: population-based and in vitro studies. Gut 2013;62:606-615.

[98] Bhalla K, Hwang BJ, Dewi RE, Twaddel W, Goloubeva OG, Wong KK, et al. Metformin prevents liver tumorigenesis by inhibiting pathways driving hepatic lipogenesis. Cancer Prev Res (Phila) 2012;5:544-552.

[99] Zhang Z], Zheng Z], Shi R, Su Q, Jiang Q, Kip KE. Metformin for liver cance prevention in patients with type 2 diabetes: a systematic review and metaanalysis. J Clin Endocrinol Metab 2012;97:2347-2353.

[100] Wu CW, Farrell GC, Yu J. Functional role of peroxisome-proliferatoractivated receptor gamma in hepatocellular carcinoma. J Gastroentero Hepatol 2012;27:1665-1669.

[101] Okumura T. Mechanisms by which thiazolidinediones induce anti-cancer effects in cancers in digestive organs. J Gastroenterol 2010;45:1097-1102.

[102] Singh S, Singh PP, Singh AG, Murad MH, Sanchez W. Statins are associated with a reduced risk of hepatocellular cancer: A systematic review and metaanalysis. Gastroenterology 2013;144:323-332.

[103] Cao Z, Fan-Minogue H, Bellovin DI, Yevtodiyenko A, Arzeno J, Yang Q, et al. MYC phosphorylation, activation, and tumorigenic potential in hepatocellular carcinoma are regulated by HMG-CoA reductase. Cancer Res 2011;71: 2286-2297.

[104] Demierre MF, Higgins PD, Gruber SB, Hawk E, Lippman SM. Statins and cancer prevention. Nat Rev Cancer 2005;5:930-942.

[105] Wang YD, Chen WD, Moore DD, Huang W. FXR: a metabolic regulator and cell protector. Cell Res 2008;18:1087-1095.

[106] Huang W, Ma K, Zhang J, Qatanani M, Cuvillier J, Liu J, et al. Nuclear receptor-dependent bile acid signaling is required for normal liver regeneration. Science 2006;312:233-236.

[107] Modica S, Murzilli S, Salvatore L, Schmidt DR, Moschetta A. Nuclear bile acid receptor FXR protects against intestinal tumorigenesis. Cancer Res 2008; 68:9589-9594.

[108] Deuschle U, Schuler J, Schulz A, Schluter T, Kinzel O, Abel U, et al. FXR controls the tumor suppressor NDRG2 and FXR agonists reduce liver tumor growth and metastasis in an orthotopic mouse xenograft model. PLoS One 2012; 7:e43044.

[109] Wolfe A, Thomas A, Edwards G, Jaseja R, Guo GL, Apte U. Increased activation of the Wnt/beta-catenin pathway in spontaneous hepatocellular carcinoma observed in farnesoid $\mathrm{X}$ receptor knockout mice. J Pharmacol Exp Ther 2011;338:12-21.

[110] Jiang Y, Iakova P, Jin J, Sullivan E, Sharin V, Hong IH, et al. Farnesoid X receptor inhibits gankyrin in mouse livers and prevents development of liver cancer. Hepatology 2013;57:1098-1106.

[111] Mann RE, Smart RG, Govoni R. The epidemiology of alcoholic liver disease. Alcohol Res Health 2003;27:209-219.

[112] Jepsen P, Ott P, Andersen PK, Sorensen HT, Vilstrup H. Risk for hepatocellular carcinoma in patients with alcoholic cirrhosis: a Danish nationwide cohort study. Ann Intern Med 2012;156:841-847.

[113] Fung J, Lai CL, But D, Wong D, Cheung TK, Yuen MF. Prevalence of fibrosis and cirrhosis in chronic hepatitis B: implications for treatment and management. Am J Gastroenterol 2008;103:1421-1426.

[114] Yim HJ, Lok AS. Natural history of chronic hepatitis B virus infection: what we knew in 1981 and what we know in 2005. Hepatology 2006;43:S173-181.

[115] Alter MJ, Kruszon-Moran D, Nainan OV, McQuillan GM, Gao F, Moyer LA, et al. The prevalence of hepatitis C virus infection in the United States, 1988 through 1994. N Engl J Med 1999;341:556-562.

[116] Niederau C, Lange S, Heintges T, Erhardt A, Buschkamp M, Hurter D, et al. Prognosis of chronic hepatitis $\mathrm{C}$ : results of a large, prospective cohort study. Hepatology 1998;28:1687-1695. 